\title{
Tourism demand modelling and forecasting: how should demand be measured?
}

\author{
HAIYAN SONG \\ School of Hotel and Tourism Management, The Hong Kong Polytechnic University, \\ Hung Hom, Kowloon, Hong Kong SAR, PR China. E-mail: bmsong@polyu.edu.bk.
}

GANG LI

Faculty of Management and Law, University of Surrey, Guildford GU2 7XH, UK.

\section{STEPHEN F. WITT AND BAOGANG FEI}

School of Hotel and Tourism Management, The Hong Kong Polytechnic University, Hung Hom, Kowloon, Hong Kong SAR, PR China.

Tourist arrivals and tourist expenditure, in both aggregate and per capita forms, are commonly used measures of tourism demand in empirical research. This study compares these two measures in the context of econometric modelling and the forecasting of tourism demand. The empirical study focuses on demand for Hong Kong tourism by residents of Australia, the UK and the USA. Using the general-to-specific modelling approach, key determinants of tourism demand are identified based on different demand measures. In addition, the forecasting accuracy of these demand measures is examined. It is found that tourist arrivals in Hong Kong are influenced mainly by tourists' income and 'word-of-mouth'/habit persistence effects, while the tourism price in Hong Kong relative to that of the tourist origin country is the most important determinant of tourist expenditure in Hong Kong. Moreover, the aggregate tourism demand models outperform the per capita models, with aggregate expenditure models being the most accurate. The implications of these findings for tourism decision making are that the choice of demand measure for forecasting models should depend on whether the objective of the decision maker is to maximize tourist arrivals or expenditure (receipts), and also that the models should be specified in aggregate form.

Keywords: tourist arrivals; tourist expenditure; forecasting accuracy; Hong Kong

Tourism demand is usually regarded as a measure of visitors' use of a good or service (Frechtling, 2001). The concept of tourism demand originated from the classical definition of demand in economics, namely the desire to possess a 
commodity or to make use of a service, combined with the ability to purchase it. 'The significance level and repercussions of tourism demand provide a strong case for better understanding of the nature of the tourists' decision-making process' (Sinclair and Stabler, 1997, p 15). Tourism demand is a special form of demand in that a tourism product is a bundle of complementary goods and services (Morley, 1992). Consumers instead of goods and services are transported, and tourism consumption occurs simultaneously with tourism production (Schulmeister, 1979).

Tourism demand can be measured in a variety of ways. Kim (1988, p 25) categorized the measurement criteria for all types of travel and tourism demand into four groups: (i) a doer criterion: such as the number of tourist arrivals, the number of tourist visits and the visit rate; (ii) a pecuniary criterion: for example the level of tourist expenditure (receipts) and share of expenditure (receipts) in income; (iii) a time-consumed criterion: such as tourist-days, tourist-nights; and (iv) a distance-travelled criterion: for instance, the distance travelled in miles or kilometres. Among the above four categories, the doer criterion and pecuniary criterion dominate international tourism demand studies. Considering statistical availability and consistency between data sources, tourist arrivals (TA) and tourist expenditure (TE) (receipts) are the most commonly used tourism demand measures in empirical studies, along with their derivatives, such as the tourist participation rate derived from tourist arrivals divided by population of the origin country/region (TA_P), and tourist expenditure per capita derived from total tourist expenditure divided by population $\left(T E \_P\right)$. Other variations of tourism demand measures can also be identified in empirical studies. Based on published studies over the periods from 1961 to the early 1990s, Crouch (1994) and Lim (1997) summarized tourism demand measures into five and six broad categories, respectively. In Crouch's (1994) review, 19 out of 80 published studies used more than one tourism demand measure. This phenomenon was also observed by Lim (1997). Li et al (2005) reviewed the literature on tourism demand modelling and forecasting using econometric approaches published over the period 1990-2004 and found that 20 measures of tourism demand were used in those studies. In addition, 18 out of 84 studies included in the review used more than one demand measure. Based on Crouch's categorization, Table 1 summarizes the applications of various tourism demand measures in the studies reviewed by Crouch (1994), Lim (1997) and Li et al (2005), respectively. It can be seen that the tourism demand measures TA (and TA_P) and TE (and TE_P) have dominated tourism demand modelling and forecasting studies over the past four decades. The following discussion will therefore focus on these two sets of measures of tourism demand.

\section{Tourist arrivals versus tourist expenditure}

Although both tourist arrivals and tourist expenditure are commonly used measures in tourism demand modelling and forecasting, the differences between the two should not be ignored.

First, the fundamental difference between these two measures is the way in which these two types of data are collected. International tourist arrivals are 
Table 1. Tourism demand measures identified in previous review studies.

$$
\text { Crouch (1994) }
$$

\section{1}

40

Tourist expenditure (receipts)

Length of stay

Nights spent at tourist accommodation

Others

Total studies reviewed

Periods of publications under review
$\operatorname{Lim}(1997)$

Li et al (2005)

53

24

49

6

4

9

100

1961-1994
0

1

10

84

often recorded by frontier counts, while tourist expenditure data are normally collected through visitor surveys (Witt and Witt, 1995). Due to the differences in data compilation, the trends and patterns of tourism demand reflected in the time series can be different, and this issue will be discussed below.

Secondly, the two demand measures serve different purposes. Tourism product/service suppliers are more interested in tourist volumes because they have direct impacts on their supply capacity. For example, the decisions on investment in new hotels and new aircraft rely largely on accurate forecasts of tourist arrivals (Sheldon, 1993, p 18). However, the tourist volume measure cannot meet the forecasting needs of economic planners because it does not take account of the economic impact of tourism on the related sectors/activities. Tourist expenditure (that is, the receipts of the destination) is the main concern of governments and central banks. However, as a foundation on which the economic impact of tourism activities is assessed, they very often do not provide adequate information and usually suffer from biases due to problems in the data collection process, as well as linkages and leakages in the economy (Frechtling, 1987).

Thirdly, when the evolution of the data series over time is considered, different patterns in the arrivals and expenditures series emerge for most destination/origin country pairs. Sheldon (1993) studied the percentage changes in international tourist expenditure and arrivals for 15 OECD countries and concluded that international tourist arrivals fluctuated to different degrees than did international tourist expenditures. This study further explained that the different fluctuation patterns were likely to do with the length of tourist stay and fluctuations in exchange rates, as well as other economic factors such as income in the tourist origin country and relative tourism prices. However, Sheldon (1993) only investigated the accuracy of tourist expenditure forecasts generated by various models and did not compare the forecasting accuracy of the demand models using different measures of tourism demand. García-Ferrer and Queralt (1997) noticed the different annual growth rates between tourist receipts and arrivals in Spain and speculated that these differences might be a result of distinctive tourist behaviours and raised the question about the choice of the relevant variable to measure tourism demand. They also suspected that the explanatory variables employed added little to the explanatory power of the evolution of international tourism demand. But they did not explore this issue further in their econometric analyses by examining the differences in the 
key determinants of the two demand measures. Moreover, they reported the forecasts of tourist expenditure only, but not those of tourist arrivals. Hence, there was no comparison of forecasting accuracy between the two measures. Qiu and Zhang (1995) attempted to make an empirical comparison between tourist arrivals and tourist expenditure in tourism demand analysis, but their focus was only on the choice of proper functional form (linear or log-linear). The estimated models were the general autoregressive distributed lag models (ADLMs), which included both statistically significant and insignificant variables. Thus, it is not possible to compare the different determinants of the two demand variables. Additionally, the forecasting accuracy of the alternative models with different tourism demand measures was not examined. The applications of ADLMs to recent tourism demand modelling and forecasting studies were summarized by Song and Li (2008).

Fourthly, with regard to tourism demand forecasting, the literature has focused mainly on comparing the forecasting performance of alternative models based on the same tourism demand measure. No attempt has been made to examine the forecasting accuracy of different demand measures systematically.

In light of the above gaps in the literature, it is necessary to investigate comprehensively the underlying factors that contribute to the different demand patterns measured by the two variables and the impacts of the selection of the demand measure on the accuracy of tourism demand forecasts. This study aims to achieve this objective and a particular focus is to examine whether the different trends/patterns in tourism demand are, in fact, caused by different factors using the econometric approach. Both dependent variables in total and per capita forms are considered, and the general-to-specific modelling approach is used to decide which factors influence the demand for tourism as defined by the two types of measure. Furthermore, this study examines the impact of using different measures in the demand models on the forecasting performance of these models.

\section{Demand for Hong Kong tourism}

Achieving an average annual growth rate of $11.1 \%$, which was higher than most of the destinations in the Asia Pacific region during the same period, international visitor arrivals in Hong Kong increased from 0.93 million in 1975 to 25.25 million in 2006. Hong Kong was ranked 16th in the World Tourism Organization's (UNWTO) list of top destinations in 2006 in terms of the number of visitor arrivals. The growth rate of visitor arrivals in Hong Kong in 2006 was $8.1 \%$, while the world and regional average growth rates in the same year were $4.5 \%$ and $7.6 \%$, respectively. Meanwhile, the growth of tourism receipts rose from $\mathrm{HK} \$ 2,975$ million in 1975 to $\mathrm{HK} \$ 89,398$ million in 2006, giving an annual growth rate of $11.6 \%$ and $5.8 \%$ in nominal and real terms, respectively. Tourism receipts grew rapidly during the 1970s and 1980s in particular and this trend continued until the mid-1990s. Tourism has become the second largest foreign currency earner since 1995 and the income generated from tourism has contributed around 6\% to Hong Kong's gross domestic product (GDP) over the past decade (Zhang et al, 2001). The Asian financial crisis caused a significant decline in tourism receipts in 1997 and 1998, with 
a huge drop in visitor numbers from the affected countries. Meanwhile, price reduction also played a significant role in the reduction of tourism revenue.

The demand for Hong Kong tourism by tourists from three long-haul markets - Australia, the UK and the USA - is chosen as the focus of this research, because they are relatively mature tourism source markets for Hong Kong and the results produced should be more representative. Figures 1-4 show total tourist arrivals, total tourist expenditure (in real terms), tourist arrivals per capita and real tourist expenditure per capita, respectively, from the three source markets. Figures 1 and 3 show that tourist arrivals from all the three markets, in both aggregate and per capita terms, have grown steadily during the period 1981-2006. On the contrary, Figures 2 and 4 suggest that real tourist expenditure decreased in the 1990s across all these markets, and most significantly in the Australian market. This is most likely due to the global economic downturns in many industrial nations over this period. It was also observed that some mega events, such as the outbreak of the Severe Acute Respiratory Syndrome (SARS) in 2003, influenced tourism demand to Hong Kong dramatically. With regard to the growth rates of both visitor arrivals and their expenditures in Hong Kong from the three main source markets, Figures 5-7 suggest that their evolution has differed substantially. For instance, the demand for Hong Kong tourism by Australian residents experienced remarkable growth in 1984 against the previous year, with an annual growth rate of $21.9 \%$ in terms of tourist arrivals. However, the demand grew only modestly, with an annual rate of $1.7 \%$ in terms of tourist expenditure over the same period (see Figure 5). More interestingly, arrivals grew year by year over the period 1992 1994, while the opposite trend was observed with tourist expenditure. Overall, there were 18 out of 24 cases where the gaps between the growth rates of tourist arrivals and expenditures were greater than 5 percentage points. As far as the UK and the USA were concerned, the cases were 16 and 15 out of 24 , respectively. With respect to the direction of the demand changes, opposite signs (positive/negative) were found in 7, 6 and 8 out of 24 cases for Australia, the UK and the USA, respectively.

\section{The model}

\section{Determinants of tourism demand}

Tourism demand could be affected by a wide range of factors, such as economic, attitudinal and political factors, but the majority of the econometric studies tend to examine the demand for tourism by focusing predominantly on economic factors. Income and prices play important roles in determining tourism demand. Crouch (1994) reveals that income is the most important explanatory variable and the income elasticity generally exceeds unity but is below two, which implies that international travel is still regarded as luxury consumption. Economic theory also indicates that the price of tourism products/ services is related negatively to tourism demand. The price variables should include the prices of the goods and services related to both the destination and substitute destinations. Additionally, marketing expenditure, consumer tastes, consumer expectations, habit persistence, origin population and one-off events 


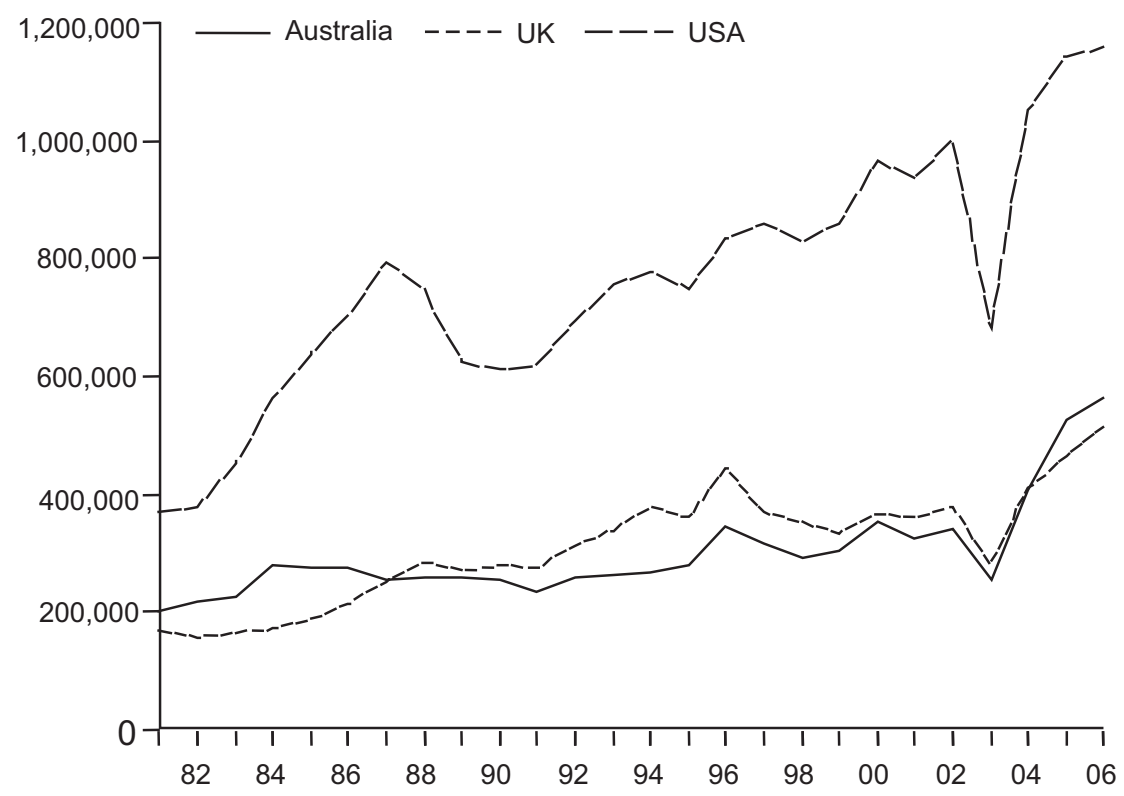

Figure 1. Tourist arrivals in Hong Kong from Australia, the UK and the USA (1981-2006).

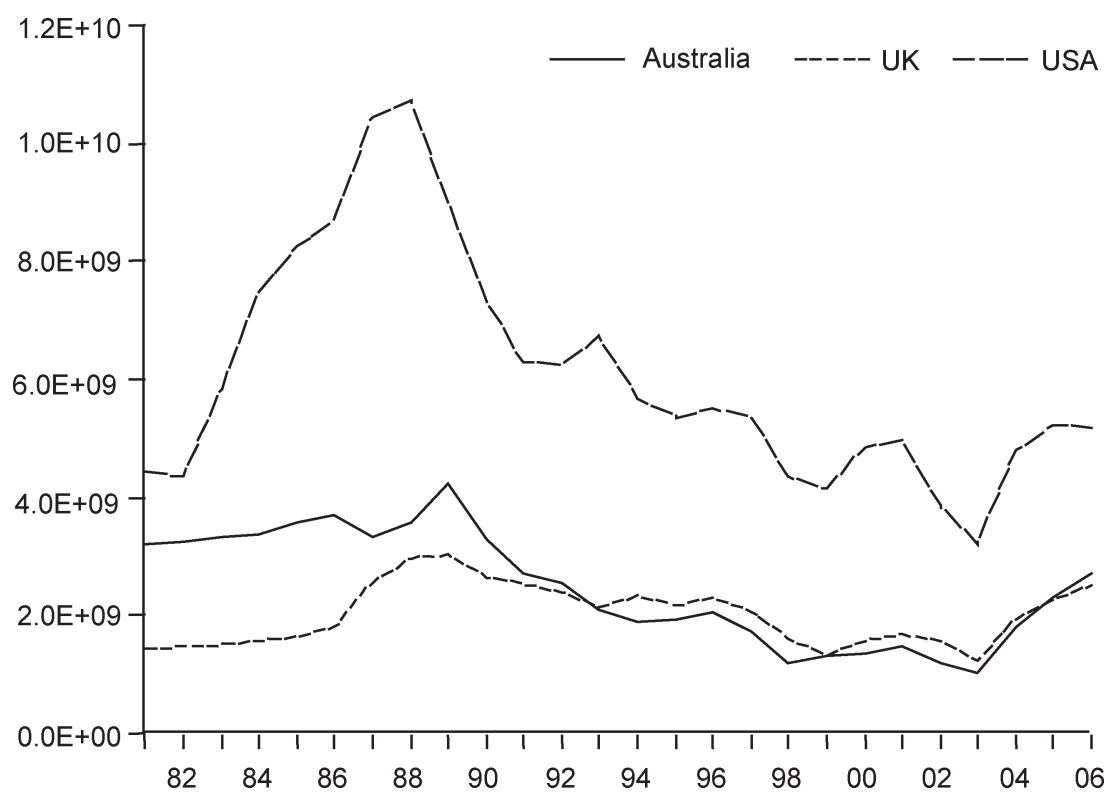

Figure 2. Real tourist expenditure in Hong Kong by visitors from Australia, the UK and the USA (1981-2006). 


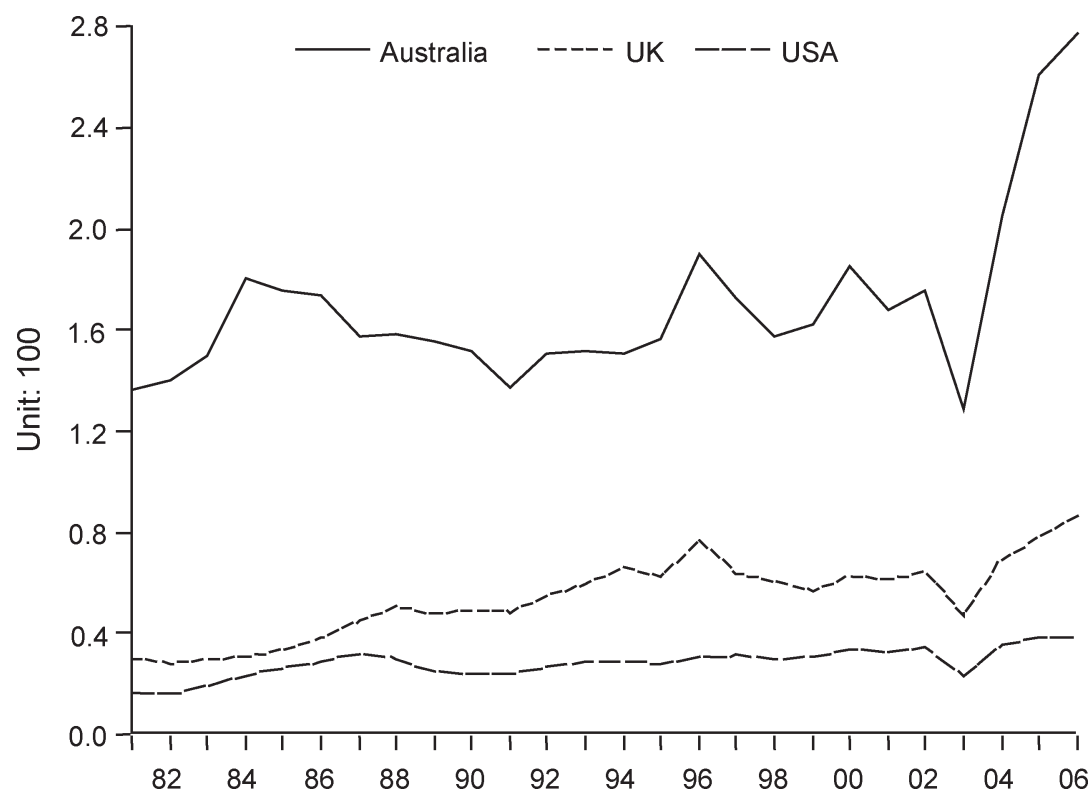

Figure 3. Tourist arrivals per capita in Hong Kong from Australia, the UK and the USA (1981-2006).

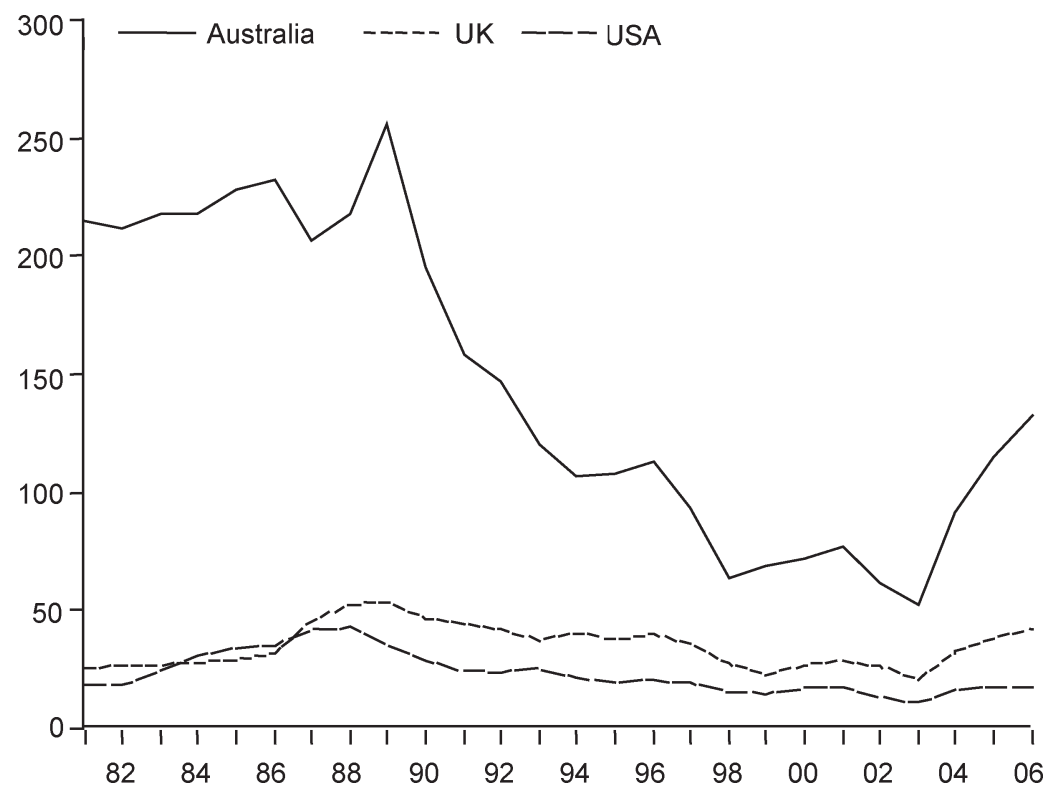

Figure 4. Real tourist expenditure per capita in Hong Kong by visitors from Australia, the UK and the USA (1981-2006). 


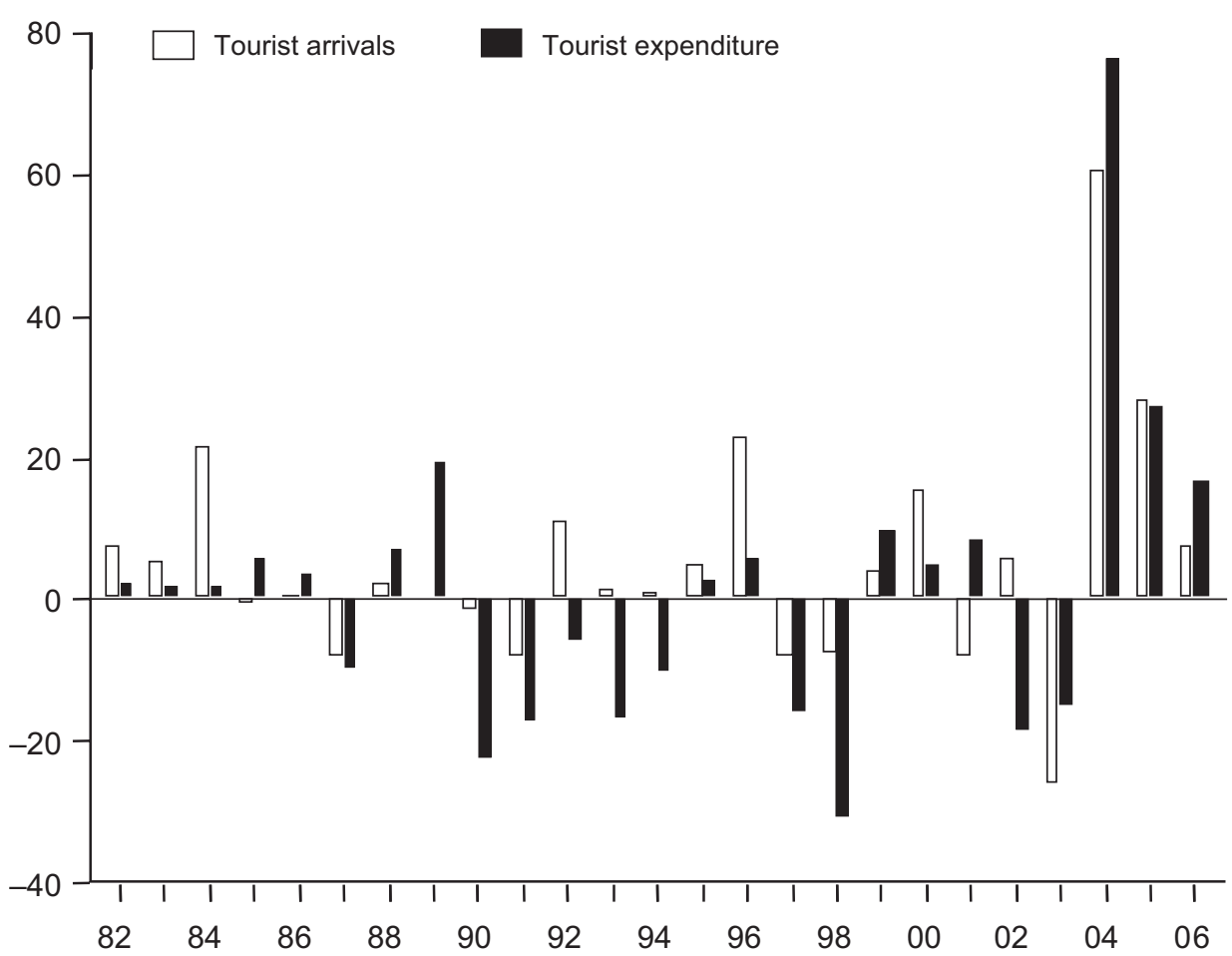

Figure 5. Annual growth rates (\%) of tourist arrivals and tourist expenditure in Hong Kong by visitors from Australia (1982-2006).

are all potentially important factors that could be incorporated into the tourism demand model (Song and Witt, 2000). Witt and Witt (1995) suggested that the time trend could represent changing tourists' tastes. The lagged dependent variable describes tourists' expectations, habit persistence, the 'word-of-mouth' effect and supply constraints. Lagged explanatory variables are also often included in demand models to capture the dynamic effects of various influencing factors on tourism demand (Lim, 1997). Fewer studies have included the marketing expenditure variable in their empirical analyses because of the unavailability of marketing expenditure data, even though promotion is generally recognized as an important strategy to enhance the awareness of a destination and to highlight its attractiveness so as to increase the number of tourists and tourism receipts. Therefore, the most commonly considered influencing factors for tourism demand in econometric models are origin income, the own price of a destination, substitute prices of alternative destinations and dummy variables to capture the effects of one-off events. These variables are also considered in the current study.

Real GDP instead of household disposable income is chosen in this study to measure the income level of an origin country. The reason for this is because of the high proportion of business visitors in overall inbound tourist arrivals in Hong Kong. Tourism price and exchange rates are jointly taken into account 


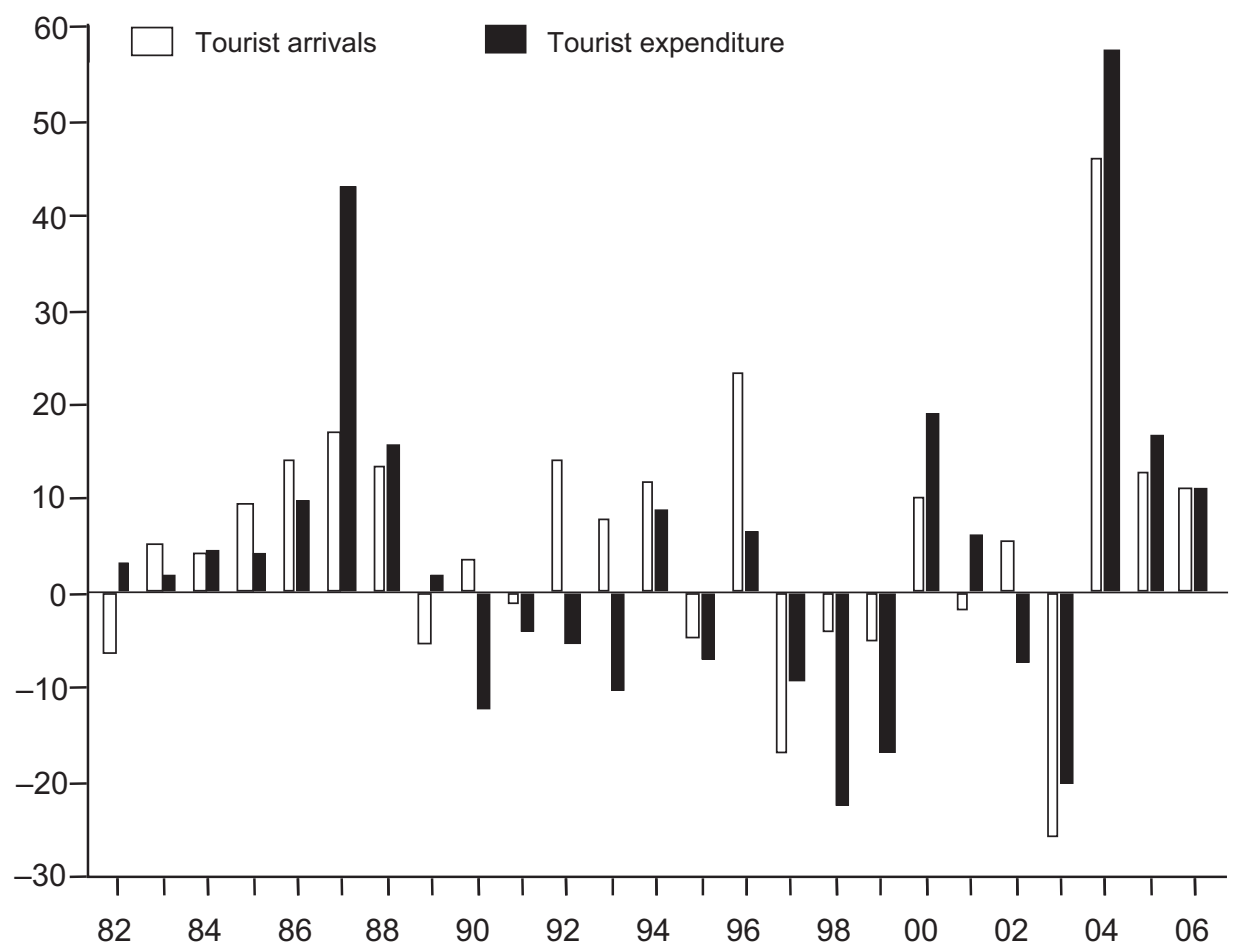

Figure 6. Annual growth rates (\%) of tourist arrivals and tourist expenditure in Hong Kong by visitors from the UK (1982-2006).

in calculating the two relative price variables in this study, that is, the own price and substitute prices. With regard to the own price of tourism in Hong Kong, it is defined as

$$
P_{i t}=\frac{C P I_{H K t} / E X_{H K t}}{C P I_{i t} / E X_{i t}},
$$

where $C P I_{H K t}$ and $C P I_{i t}$ are the consumer price indices (CPIs) for Hong Kong and origin country $i$, respectively; $E X_{H K t}$ and $E X_{i t}$ are the exchange rates between the Hong Kong dollar and the US dollar and between the currency of origin country $i$ and the US dollar, respectively. The exchange rates are measured by the annual average market rates of the local currency against the US dollar. The own-price variable defined above is a 'relative' or 'effective price of tourism' (Durbarry and Sinclair, 2005, p 981). It reflects the costs of tourism activities in Hong Kong relative to those in the tourist's origin country. It embodies a plausible decision-making process by a tourist, that is, a decision between domestic and international tourism. In other words, domestic tourism is regarded as a substitute for international tourism, or at least used as a benchmark when a tourist plans his or her international travel.

After taking account of both geographic and cultural characteristics, 


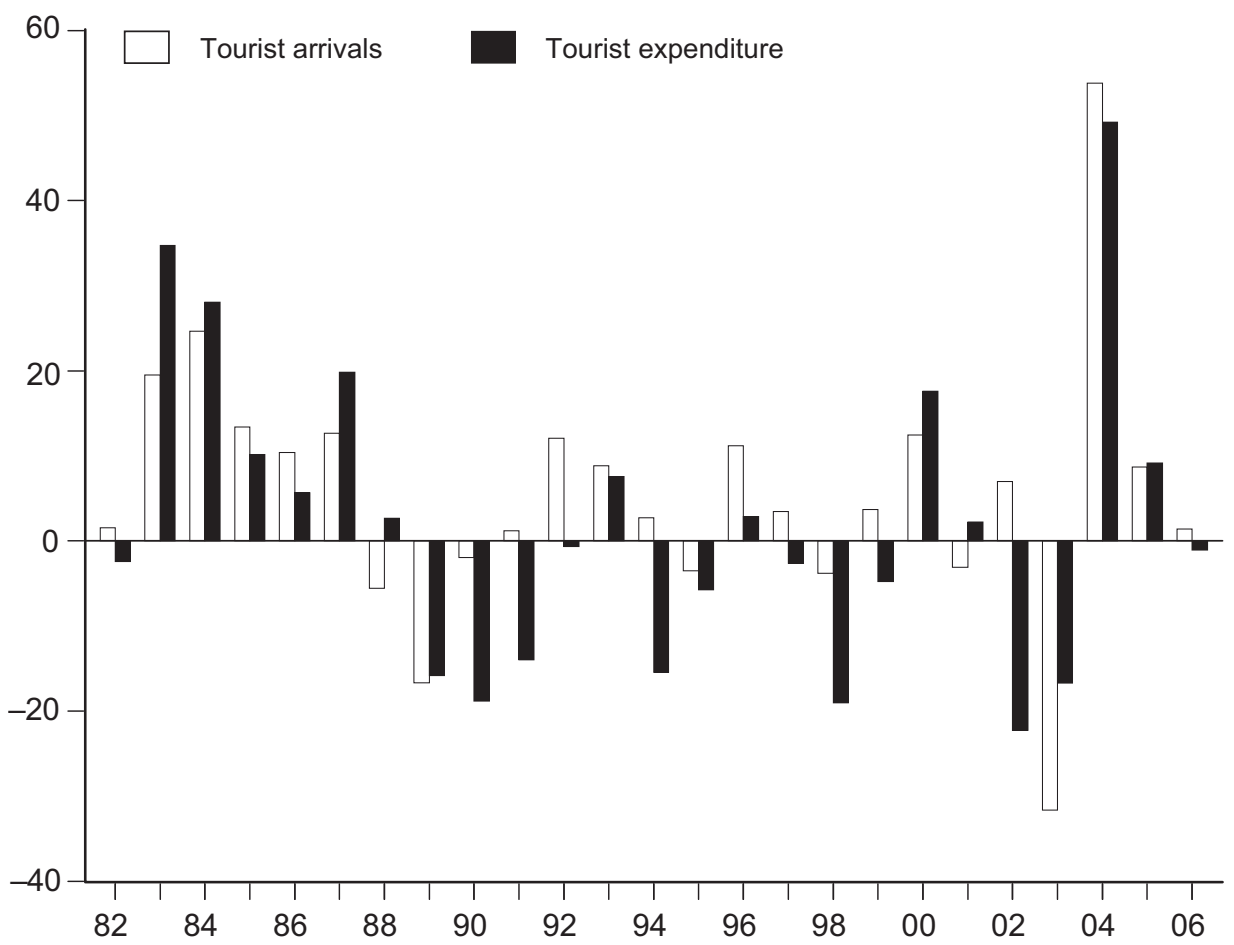

Figure 7. Annual growth rates (\%) of tourist arrivals and tourist expenditure in Hong Kong by visitors from the USA (1982-2006).

mainland China, Singapore, South Korea, Taiwan and Thailand are selected to be the substitute destinations for Hong Kong in this study. Following Song et al (2003) and Gallet and Braun (2001), the substitute price variable is defined as a weighted average index of the selected countries'/regions' tourism prices, namely

$$
P_{s t}=\sum_{j=1}^{5} \frac{C P I_{j t}}{E X_{j t}} w_{i j t},
$$

where $j=1,2,3,4$ and 5 represent the five substitute destinations, respectively; and $w_{i j t}$ is the share of international tourist arrivals to country/region $j$ and is calculated from

$$
w_{i j t}=T A_{i j t} / \sum_{j=1}^{5} T A_{i j t},
$$

where $T A_{i j t}$ is the inbound tourist arrivals to substitute destination $j$ from the origin country/region $i$ at time $t$. The above formula indicates that the weights for calculating the substitute price variable change over time in order to reflect the dynamics of the substitution effect. It should be noted that to ensure the comparability of the model estimations using the two sets of demand measures, the same definition of the substitute price variable is adopted across all models 
with different measures of tourism demand. In other words, the weights for the substitute price calculation are always tourist arrivals, regardless of the dependent variable. Although the patterns of historical evolutions of tourist arrivals and tourist expenditure are different as far as the same destination is concerned, as discussed above, the proportions of market shares among a few destinations measured by tourist arrivals are highly consistent with those measured by tourist expenditure at each point of time. Therefore, the choice of the weighing scheme does not have a significant effect on the variations of the calculated substitute price variable. Real GDP, CPI and exchange rates here take the forms of indices, and their values in 2000 are specified as 100. Such rescaling does not affect the variables concerned and has no effect on the estimated coefficients of these variables in a log-linear model.

\section{The data}

The Hong Kong Tourism Board (HKTB) publishes various up-to-date key tourism data. Monthly or cumulative visitor arrivals are published by country/ territory of residence and by the mode of transport. Visitor profiles along with their expenditures are also surveyed every year. Strictly speaking, international visitors consist of international tourists and international same-day visitors, as defined by UNWTO. The actual arrivals data used in this study are international visitor arrivals by country of residence provided by the HKTB. Tourist expenditure (receipts) is defined by $\mathrm{UNWTO}^{1}$ as expenditure of outbound (inbound) visitors plus their payments to foreign (national) carriers for international transport. In this research, however, data on the inbound overnight tourist expenditure in Hong Kong are used. The expenditure of sameday visitors and all the payments made to carriers registered in Hong Kong are excluded due to incomplete statistics of same-day visitor expenditure from specific countries.

The real GDP, CPI and exchange rate data were collected from the International Financial Statistics Yearbook published by the International Monetary Fund (IMF). Where per capita demand was concerned, population data were needed and these were collected from the IMF publications. The sample period of this empirical study is from 1981 to 2006 and the observations of tourism demand are at the annual frequency.

\section{Model specification}

In this study, the following demand function is proposed to model the demand for tourism in Hong Kong by residents from each of the three origin countries:

$$
T D_{i t}=A Y_{i t}^{\beta_{2}} P_{i t}^{\beta_{3}} P_{s t}^{\beta_{4}} e_{i t}
$$

where $T D_{i t}$ is the proxy of tourism demand, that is, TA, TA_P, TE and TE_P, in Hong Kong from origin country $i$ at time $t ; Y_{i t}$ is the income level (or income per capita, $Y_{-} P_{i t}$, when TA_P and TE_P are concerned) of origin country $i$; $P_{i t}$ is the own price of tourism in Hong Kong at time $t ; P_{s t}$ is the substitute price of tourism at time $t$; and $e_{i t}$ is the error term which is used to capture the influence of all other factors that are not included in the demand model.

According to Song and Witt (2000), one major feature of the power function 
[Equation (1)] is that it can be transformed into a log-linear specification, which can be estimated easily using the ordinary least squares (OLS) method. After taking logarithms of Equation (1), we have

$$
\ln T D_{i t}=\beta_{1}+\beta_{2} \ln Y_{i t}+\beta_{3} \ln P_{i t}+\beta_{4} \ln P_{s t}+\varepsilon_{i t}
$$

where $\beta_{1}=\ln A, \varepsilon_{i t}=\ln e_{i t}$ and $\beta_{2}, \beta_{3}$ and $\beta_{4}$ are income, own-price and crossprice elasticities, respectively. To capture the influence of various one-off events on the demand for tourism in Hong Kong, a number of dummy variables are included in the above model. These dummy variables include $D_{97}\left(D_{97}=1\right.$ in 1997 and 0 otherwise) to capture the effect of the Asian financial crisis in 1997; $D_{911}\left(D_{911}=1\right.$ in 2001 and 0 otherwise $)$ to capture the effect of the September 11 terrorist attack on the USA in 2001, $D_{\text {SARS }}\left(D_{\text {SARS }}=1\right.$ in 2003 and 0 otherwise) to reflect the influence of SARS in Hong Kong in 2003; and $D_{F L U}$ $\left(D_{F L U}=1\right.$ in 2004 and 0 otherwise) to reflect the impact of avian flu.

The above equation is a static model and does not take into account the dynamics of the tourist's decision-making process. In order to capture the dynamics of tourism demand, the general specification of the ADLM is used in this study. The exact lag length of either 1 or 2 in each general ADLM is determined by the Akaike information criterion (AIC) and the Schwarz criterion (SC). The general ADLM initially takes the following form:

$$
\begin{aligned}
& \ln T D_{i t}=\alpha_{1}+\sum_{j=1}^{2} \gamma_{j} \ln T D_{i t-j}+\sum_{j=0}^{2} \lambda_{j} \ln Y_{i t-j}+\sum_{j=0}^{2} \theta_{j} \ln P_{i t-j} \\
& +\sum_{j=0}^{2} \phi_{j} \ln P_{s t-j}+\alpha_{2} D_{97}+\alpha_{3} D_{911}+\alpha_{4} D_{S A R S}+\alpha_{5} D_{F L U}+\varepsilon_{i t} .
\end{aligned}
$$

\section{Model estimation}

The general-to-specific modelling approach is applied to reduce the number of explanatory variables in the initial equation, keeping only the underlying influencing factors based on both statistical significance and the sensible economic interpretation of the estimated parameters associated with these factors. The general-to-specific approach was proposed originally by Davidson et al (1978) and modified subsequently by Hendry and von Ungern-Sternberg (1981) and Mizon and Richard (1986), but full development of the generalto-specific modelling approach has taken place only recently (see Hendry, 1995). This approach starts with a general dynamic ADLM, which includes all potentially influential factors with a sufficient lag structure. By removing statistically insignificant variables from the model one by one, starting with the least significant, the general ADLM is reduced to a more specific one with all remaining variables being significant. Following such a scientific procedure, the key determinants of tourism demand can be identified. The final specific model would be most appropriate for forecasting and policy evaluation purposes.

OLS is employed to estimate the models with the data series from 1981 to 2004, and the data for 2005 and 2006 are reserved to evaluate forecasting accuracy. Following the above general-to-specific model reduction procedure, the statistically insignificant or incorrectly signed coefficients (that is, the signs are contradictory to economic theory in Equation (3)) are removed from the 
Table 2. Estimates of Australian models.

TA

$\alpha$

7.256

$(3.980)$

$\ln T A_{i t-1}$

$0.321 * *$

(1.813)

$\ln T A_{i t-2}$

$\ln Y_{i t}$

1.784

$(2.359)$

$\ln Y_{i t-1} \quad-1.504$

$(-2.043)$

$\ln Y_{i t-2}$

$\ln P_{i t}$

$\ln P_{i t-1}$

$\ln P_{i t-2}$

$\ln P_{s t}$

$\ln P_{s t-1}$

$\ln P_{s t-2}$

$D_{97}$

0.165

(2.634)

$\mathrm{D}_{911}$

$D_{\text {SARS }}$

$-0.262$

$(-3.927)$

$D_{F L U}$

$-0.294$

$(-3.466)$

$\begin{array}{ll}R^{2} & 0.848\end{array}$

AC $\quad-2.554$

SC $\quad-2.209$

CSQN 2.246

CSQA $\quad 0.475$

CSQH $\quad 0.638$

CSQAH 1.998

CSQF $\quad 1.034$
TE

$\alpha$

21.007

(381.459)

$\ln T E_{i t-1}$

$\ln T E_{i t-2}$

$\ln Y_{i t}$

$\ln Y_{i t-1}$

$\ln Y_{i t-2}$

$\ln P_{i t}$

$\ln P_{i t-1}$

$-1.514$

$(-12.203)$

$\ln P_{i t-2}$
$\ln P_{s t}$

$\ln P_{s t-1}$

$\ln P_{s t-2}$

$D_{97}$

$\mathrm{D}_{911}$

$D_{\text {SARS }}$

$-0.339$

$(-2.215)$

$D_{F L U}$

$R^{2}$

AC

0.900

SC

$-0.905$

CSQN

$-0.757$

CSQA

2.419

$\mathrm{CSQH}$

0.649

0.620

CSQAH

2.272

CSQF

0.001
TA P

TE_P

$\alpha$

$-2.792$

$(-2.670)$

4.233

(66.449)

$\ln T A \_P_{i t-1} \quad 0.365$

(2.092)

$\ln T A \_P_{i t-2}$

$\ln Y \_P_{i t} \quad 1.613$

(2.232)

$\ln Y \_P_{i t-1} \quad-1.581$

$(-2.160)$

$\ln Y_{-} P_{i t-2}$

$\ln P_{i t}$

$\ln P_{i t-1}$

$\ln P_{i t-2}$

$\ln P_{s t}$

$-0.829$

$(-3.666)$

$\ln P_{s t-1}$

$\ln P_{s t-2}$

$D_{97}$

0.161

(2.511)

$\mathrm{D}_{911}$

$D_{\text {SARS }}$

$-0.260$

$(-3.800)$

$D_{F L U}$

$-0.310$

$(-3.603)$

$\begin{array}{ll}R^{2} & 0.687\end{array}$

AC

$-2.505$

SC

$-2.159$

CSQN

0.148

CSQA

1.551

$\mathrm{CSQH}$

0.723

CSQAH

0.020

0.010

$\ln T E_{-} P_{i t-1}$

$\ln T E \_P_{i t-2}$

$\ln Y_{-} P_{i t}$

$\ln Y \_P_{i t-1}$

$\ln Y \_P_{i t-2}$

$\ln P_{\text {it }}$

$\ln P_{i t-1}$

$(-12.527)$

$\ln P_{i t-2}$

$\ln P_{s t}$

$\ln P_{s t-1}$

$\ln P_{s t-2}$

$D_{97}$

$\mathrm{D}_{911}$

$D_{\text {SARS }}$

$-0.379$

$(-2.138)$

$D_{F L U}$

$R^{2}$

0.893

AC $\quad-0.613$

SC $\quad-0.465$

CSQN $\quad 0.102$

CSQA $\quad 1.687$

$\mathrm{CSQH} \quad 1.173$

CSQAH $\quad 0.219$

CSQF

0.108

Note: The values in parentheses are $t$-statistics. $* *$ indicates the estimate is significant at the $10 \%$ level. All other coefficients are significant at the 5\% level. CSQA, Lagrange multiplier chi-square test for serial correlation; CSQH, the White chi-square test for heteroskedasticity; CSQN, the Jarque and Bera chi-square test for non-normality; CSQAH, Engle test for autoregressive conditional heteroskedasticity; CSQF, the Ramsey misspecification test.

model. The final models that have gone through the reduction procedure are used for demand elasticity analysis and forecasting. Tables $2-4$ report the estimates of the final specific models.

In general, all the models fit the data well with relatively high adjusted $R^{2}$ s. The diagnostic statistics in the lower parts of Tables $2-4$ show that most models pass all five tests, with only two exceptions; that is, the UK TA (TA_P) and $T E$ ( $T E \_P$ ) models fail the CSQF test. Overall, given the small sample size (only 23 observations for all the variables), the estimated demand models can be regarded as well specified. 
Table 3. Estimates of UK Models.

TA

$\alpha$

2.125

(3.035)

$\ln T A_{i t-1} \quad 0.725$

(6.300)

$\ln T A_{i t-2}$

$\ln Y_{i t}$

3.107

(2.306)

$\ln Y_{i t-1} \quad-5.896$

$(-2.504)$

$\ln Y_{i t-2}$

3.192

(2.388)

$\ln P_{i t}$

$\ln P_{i t-1}$

$\ln P_{i t-2}$

$\ln P_{s t}$

$\ln P_{s t-1}$

$\ln P_{s t-2}$

$D_{97}$

0.232

(3.254)

$\mathrm{D}_{911}$

$D_{\text {SARS }}$

$-0.353$

$(-4.441)$

$D_{F L U}$

$-0.232$

$(-2.324)$

$R^{2} \quad 0.940$

AC $\quad-2.275$

SC $\quad-1.878$

CSQN 2.327

CSQA 2.908

CSQH $\quad 1.341$

CSQAH 0.107

CSQF 14.276
TE

$$
\alpha \quad 3.478
$$

(1.500)

0.778

(7.714)

$\ln T E_{i t-2}$

$\ln Y_{i t}$

4.600

(2.383)

$\ln Y_{i t-1}$

$-4.356$

$(-2.276)$

$\ln Y_{i t-2}$

$\ln P_{i t}$

$-0.641$

$(-3.849)$

$\ln P_{i t-1}$

$\ln P_{i t-2}$

$\ln P_{s t}$

$\ln P_{s t-1}$

$\ln P_{s t-2}$

$D_{97}$

$\mathrm{D}_{911}$

$D_{\text {SARS }}$

$-0.403$

$(-3.153)$

$D_{F L U}$

$R^{2}$

AC

0.807

SC

$-1.292$

CSQN

$-0.996$

CSQA

2.170

CSQH

3.020

CSQAH

1.363

CSQF

14.024
TA_P

TE_P

$\begin{array}{lc}\alpha & -0.550 \\ & (-0.584) \\ \ln T E_{-} P_{i t-1} & 0.78 \\ & (7.758) \\ \ln T E_{-} P_{i t-2} & \\ \ln Y \_P_{i t} & 4.587 \\ & (2.368)\end{array}$

$\ln Y \_P_{i t-1} \quad-4.328$

$(-2.268)$

$\ln Y \_P_{i t-2}$

$\ln P_{i t} \quad-0.638$

$(-3.848)$

$\ln P_{i t-1}$

$\ln P_{i t-2}$

$\ln P_{s t}$

$\ln P_{s t-1}$

$\ln P_{s t-2}$

$D_{97}$

(3.267)
$\mathrm{D}_{911}$

$D_{\text {SARS }}$

$-0.356$

$(-4.483)$

$D_{F L U}$

$-2.227$

$(-2.283)$

$\begin{array}{ll}R^{2} & 0.935\end{array}$

AC

$-2.28$

SC $\quad-1.88$

CSQN

0.549

CSQA

0.568

CSQH $\quad 0.891$

CSQAH 0.055

CSQF

$\mathrm{D}_{911}$

$D_{\text {SARS }}$

$-0.404$

$(-3.155)$

$D_{F L U}$

$R^{2}$

0.816

AC

$-1.29$

SC

$-0.99$

CSQN

0.548

CSQA

0.570

CSQH

0.899

CSQAH

0.049

1.057

0.971

Note: The values in parentheses are $t$-statistics. All coefficients are significant at the $5 \%$ level. CSQA, Lagrange multiplier chi-square test for serial correlation; CSQH, the White chi-square test for heteroskedasticity; CSQN, the Jarque and Bera chi-square test for non-normality; CSQAH, Engle test for autoregressive conditional heteroskedasticity; CSQF, the Ramsey misspecification test.

The results in Tables $2-4$ show that the explanatory variables in the final $T A$ and TA_P models are consistent, suggesting that these variables have significant influences on the demand for tourism in Hong Kong measured by the two arrival variables. This suggests that there is little difference between the determinants of total tourist arrivals and the arrivals per capita, that is, the tourism participation rate. Similarly, the same determinants were identified in the two models when TE and TE_P were used to measure the demand for Hong Kong tourism. 
Table 4. Estimates of USA models.

TA

$\alpha \quad 5.002$

(4.527)

$\ln T A_{i t-1} \quad 1.017$

$(5.770)$

$\ln T A_{i t-2} \quad-0.535$

$(-3.108)$

$\ln Y_{i t}$

$\ln Y_{i t-1}$

$\ln Y_{i t-2}$

0.465

(2.960)

$\ln P_{i t}$

$\ln P_{i t-1}$

$\ln P_{i t-2}$

$\ln P_{s t}$

$\ln P_{s t-1}$

$\ln P_{s t-2}$

$\mathrm{D}_{97}$

$\mathrm{D}_{911}$

$D_{\text {SARS }}$

$-0.412$

$(-5.883)$

$D_{F L U}$

$(-4.553)$

$R^{2}$

AC

0.905

SC

$-2.478$

$-2.180$

CSQN

CSQA

0.265

2.230

CSQH

0.777

CSQAH

CSQF
TE

$\alpha$

$\ln T E_{i t-1}$

$\ln T E_{i t-2}$

$\ln Y_{i t}$

$\ln Y_{i t-1}$

$\ln Y_{i t-2}$

$\ln P_{i t}$

1.815

(2.815)

$\ln P_{i t-1}$

$-2.996$

$(-4.652)$

$\ln P_{i t-2}$

$\ln P_{s t}$

$\ln P_{s t-1}$

$\ln P_{s t-2}$

$\mathrm{D}_{97}$

$\mathrm{D}_{911}$

$D_{\text {SARS }}$

$-0.474$

$(-2.938)$

$D_{F L U}$

$R^{2}$

AC

SC

CSQN

CSQA

$\mathrm{CSQH}$

CSQAH

CSQF

22.343

0.770

$-0.745$

$-0.547$

0.293

0.735

1.702
TA P

TE_P

$\alpha$

$-4.935$

$(-0.004)$

$\alpha$

2.913

(65.99)

$\ln T A \_P_{i t-1} \quad 1.014$

(5.708)

$\ln T A \_P_{i t-2}-0.530$

$(-3.032)$

$\ln Y \_P_{i t}$

$\ln Y \_P_{i t-1}$

$\ln Y{ }_{-} P_{i t-2} \quad 0.435$

(2.331)

$\ln P_{i t}$

$\ln P_{i t}$

1.783

(2.662)

$\ln P_{i t-1}$

$-3.249$

$\ln P_{i t-1}$

$(-4.858)$

$\ln P_{i t-2}$

$\ln P_{s t}$

$\ln P_{s t-1}$

$\ln P_{s t-2}$

$\mathrm{D}_{97}$

$\mathrm{D}_{911}$

$D_{\text {SARS }}$

$-0.565$

$D_{\text {SARS }}$

$-0.411$

$(-5.859)$

$(-3.378)$

$D_{F L U}$

$-0.434$

$(-4.559)$

$R^{2}$

0.837

$D_{F L U}$

AC

$-2.477$

SC $\quad-2.179$

CSQN

1.026

0.716

0.902

CSQA

0.236

CSQAH

8.210
0.839

$R^{2}$

$-0.669$

AC

$-0.472$

$\mathrm{SC}$

$\begin{array}{ll}\text { CSQN } & 1.506 \\ \text { CSQA } & 0.555\end{array}$

$\mathrm{CSQH} \quad 1.506$

CSQAH 0.986

CSQF

Note: The values in parentheses are $t$-statistics. All coefficients are significant at the 5\% level. CSQA, Lagrange multiplier chi-square test for serial correlation; CSQH, the White chi-square test for heteroskedasticity; CSQN, the Jarque and Bera chi-square test for non-normality; CSQAH, Engle test for autoregressive conditional heteroskedasticity; CSQF, the Ramsey misspecification test.

When comparing the two pairs of demand measures, that is, TA (TA_P) versus $T E\left(T E \_P\right)$, different findings are obtained. The most important determinants of TA and TA_P are income and the lagged dependent variable, together with one-off events. However, the own-price variable and the SARS outbreak are the main determinants of $T E$ and $T E \_P$. This indicates that the different fluctuations of TA (TA_P) and TE (TE_P) can be explained best by different influencing factors. It seems that the 'word-of-mouth'/habit persistence effects (measured by the lagged dependent variable) and the origin income level stimulate tourists' actual visits to Hong Kong, but this does not translate into 
the expected dollar income for the Hong Kong economy. On the other hand, the price of Hong Kong tourism relative to that of domestic tourism in the source markets is the major determinant of tourists' expenditure. In addition, the responses of TE and TA to one-off events are found to be different. $D_{97}$, $D_{\text {SARS }}$ and $D_{F L U}$ are all significant influencing factors in the TA (TA_P) models, while only $D_{\text {SARS }}$ shows a significant effect on TE (TE_P). This indicates that tourist arrivals are more likely to be subject to the influences of one-off events than tourist expenditure.

Interestingly, substitute prices are excluded from almost all the models. This implies that substitute prices do not play a major role in determining the demand for Hong Kong tourism by tourists from the three origin countries. This low substitutability reflects the uniqueness of the tourism offerings in Hong Kong and the strong comparative advantage of Hong Kong tourism in the region.

It should be noted that the differences in sample periods, lag structures of the general ADLM and the inclusion of different explanatory variables all contribute to the discrepancies of the model estimation results between the current study and the other relevant studies. However, some consistencies have also been observed. For instance, with regard to UK outbound tourism demand, insignificant effects of destination prices on tourist arrivals have been reported by Song et al (2003) in the case of UK aggregate demand for Thai tourism, and by Kulendran and Witt (2001) in the case of UK per capita demand for tourism to Greece, the Netherlands and the USA.

The finding that $T A\left(T A \_P\right)$ and $T E\left(T E \_P\right)$ are affected by different economic factors provides useful information for practitioners. Assuming that there was a deficit in the balance of payments, more foreign exchange receipts might be desired rather than increasing the number of tourist arrivals. In this situation, an appropriate pricing strategy that encourages tourist expenditure would be desirable. This is also essential as far as tourism businesses (such as hotels) are concerned in terms of their effective yield management. According to the model estimation results, it seems that although price adjustments (such as in promotions or price discounts) may not attract a greater number of guests to a hotel, they are likely to increase a hotel's revenue by extending the length of the guests' stay in the hotel. Since the model estimation results have shown that various crises affect tourist expenditure significantly, proper pricing strategies and timely price adjustments are likely to be effective in crisis situations.

\section{Forecasting evaluation}

To examine the forecasting accuracy of the alternative models, one-step-ahead ex post forecasts are generated for 2005 and 2006 by each model. As with most tourism forecasting studies, the mean absolute percentage error (MAPE) and root mean square percentage error (RMSPE) are used to measure accuracy. The values and mean ranks of the models for each country are presented in Table 5. Generally speaking, most of the models generate relatively accurate forecasts, with MAPEs being less than 6\%. The performance of each of the four models is highly consistent across the three origin countries. The TE model is 
Table 5. Forecasting performance measured by MAPE and RMSPE.

\begin{tabular}{lrlllllll}
\hline & \multicolumn{2}{c}{ Australia } & \multicolumn{2}{c}{ UK } & \multicolumn{2}{c}{ USA } & \multicolumn{2}{c}{ Overall } \\
& MAPE & RMSPE & MAPE & RMSPE & MAPE & RMSPE & MAPE & RMSPE \\
$T A$ & $2.978(2)$ & $2.979(3)$ & $0.788(2)$ & $0.813(2)$ & $0.507(1)$ & $0.684(1)$ & $1.424(2)$ & $1.480(2)$ \\
$T A \_P$ & $10.580(4)$ & $2.557(2)$ & $2.108(3)$ & $2.168(3)$ & $1.259(3)$ & $1.680(3)$ & $4.625(3)$ & $2.135(3)$ \\
$T E$ & $0.316(1)$ & $0.365(1)$ & $0.425(1)$ & $0.455(1)$ & $0.676(2)$ & $0.686(2)$ & $0.472(1)$ & $0.502(1)$ \\
$T E \_P$ & $5.203(3)$ & $5.242(4)$ & $2.526(4)$ & $2.692(4)$ & $10.185(4)$ & $10.259(4)$ & $5.996(4)$ & $6.060(4)$ \\
\hline
\end{tabular}

Note: The figures in parentheses refer to the ranks of forecasting performance of the models.

the best-performing model across all the three source markets, followed by the $T A, T A \_P$ and TE_P models. Table 5 shows that the forecasts of the aggregate demand models are more accurate than the forecasts of the per capita demand models, which implies that the inclusion of the origin country population in tourism demand models is not beneficial in generating accurate forecasts.

\section{Conclusion}

Tourist arrivals and tourist expenditure are both regarded as plausible measures of tourism demand, which have been used frequently in tourism demand modelling and forecasting. However, little empirical research has been undertaken on comparing the appropriateness of these two alternative measures in identifying the key determinants of tourism demand and forecasting performance when different measures of demand are used in the modelling process. This study uses data on the demand for Hong Kong tourism by three key source markets and tests the suitability of the two alternative tourism demand measures in tourism demand modelling and forecasting. The empirical results show that the different patterns of TA $\left(T A \_P\right)$ and $T E\left(T E \_P\right)$ fluctuation are likely to be driven by different influencing factors. Tourist arrivals (both $T A$ and $\left.T A \_P\right)$ are more likely to be affected by origin country income and 'word-of-mouth'/habit persistence effects, while tourist expenditure is driven mainly by destination prices relative to those in the origin country. The forecasting performance of the four models estimated using different dependent variables is also investigated and the results show that aggregate expenditure can be predicted most accurately, followed by total visits and per capita visits, while forecasts of the per capita expenditure are the poorest. The practical implications of these findings are that: firstly, econometric models of tourism demand used for forecasting purposes should be estimated in aggregate form instead of per capita form; and secondly, in order to devise effective tourism policies and strategies to increase tourism demand, attention should be paid to the particular measure of tourism demand of interest and its corresponding economic determinants.

It should be noted that the conclusions drawn from this study are based on a particular data set related to the demand for Hong Kong tourism. Therefore, any attempt to generalize the findings should be made with caution, although the methodology and procedure are readily applicable to the investigation of 
other destination-origin country/region pairs across different time horizons. Possible extensions of this research are to employ larger data sets and also to use panel data analysis to verify the empirical results obtained in this study.

\section{Endnotes}

1. UNWTO also uses the term 'tourism expenditure' to refer to aggregate spending of tourists in a destination. Tourist expenditure and tourism expenditure are used interchangeably in this study.

\section{References}

Crouch, G.I. (1994), 'The study of international tourism demand: a survey of practice', Journal of Travel Research, Vol 32, pp 41-54.

Davidson, J., Hendry, D.F., Saba, F., and Yeo, S. (1978), 'Econometric modelling of the aggregate time series relationships between consumers expenditure and income in the United Kingdom', Economic Journal, Vol 88, pp 661-692.

Durbarry, R., and Sinclair, M.T. (2005), 'Tourism competitiveness: price and quality', Tourism Economics, Vol 11, pp 45-68.

Frechtling, D. (1987), 'Assessing the impact of travel and tourism - measuring economic benefits', in Ritchie, J.B., and Goeldner, C.R., eds, Travel, Tourism and Hospitality Research Handbook, John Wiley, New York, pp 325-331.

Frechtling, D. (2001), Forecasting Tourism Demand: Methods and Strategies, Butterworth-Heinemann, Oxford.

Gallet, C.A., and Braun, B.M. (2001), 'Gradual switching regression estimates of tourism demand', Annals of Tourism Research, Vol 28, pp 503-507.

García-Ferrer, A., and Queralt, R. (1997), 'A note on forecasting international tourism demand in Spain', International Journal of Forecasting, Vol 13, pp 539-549.

Hendry, D.F. (1995), Dynamic Econometrics: An Advanced Text in Econometrics, Oxford University Press, Oxford.

Hendry, D.F., and von Ungern-Sternberg, T. (1981), 'Liquidity and inflation effects on consumers' expenditure', in Deaton, A., ed, Essays in the Theory and Measurement of Consumers' Behaviour, Cambridge University Press, Cambridge, pp 237-261.

Kim, S.H. (1988), 'The demand for international travel and tourism to South Korea: an econometric evaluation of major economic factors', $\mathrm{PhD}$ thesis, University of Santo Tomas, Manila.

Kulendran, N., and Witt, S.F. (2001), 'Cointegration versus least squares regression', Annals of Tourism Research, Vol 28, pp 291-311.

Li, G., Song, H., and Witt, S.F. (2005), 'Recent developments in econometric modeling and forecasting', Journal of Travel Research, Vol 44, pp 82-99.

Lim, C. (1997), 'Review of international tourism demand models', Annals of Tourism Research, Vol 24, pp 835-849.

Mizon, G.E., and Richard, J.F. (1986), 'The encompassing principle and its application to testing non-nested hypotheses', Econometrica, Vol 54, pp 657-678.

Morley, C. (1992), 'A microeconomic theory of international tourism demand', Annals of Tourism Research, Vol 19, pp 250-267.

Qiu, H., and Zhang, J. (1995), 'Determinants of tourist arrivals and expenditures in Canada', Journal of Travel Research, Vol 34, pp 43-49.

Schulmeister, S. (1979), Tourism and the Business Cycle: Econometric Models for the Purpose of Analysis and Forecasting of Short-Term Changes in the Demand for Tourism, Austrian Institute for Economic Research, Vienna.

Sheldon, P.J. (1993), 'Forecasting tourism: expenditure versus arrivals', Journal of Travel Research, Vol 32, pp 13-20.

Sinclair, M.T., and Stabler, M. (1997), The Economics of Tourism, Routledge, London.

Song, H., and Li, G. (2008), 'Tourism demand modelling and forecasting - a review of recent research', Tourism Management, Vol 29, pp 203-220.

Song, H., and Witt, S.F. (2000), Tourism Demand Modelling and Forecasting: Modern Econometric Approaches, Pergamon, Oxford. 
Song, H., Witt, S.F., and Li, G. (2003), 'Modelling and forecasting the demand for Thai tourism', Tourism Economics, Vol 9, pp 363-387.

Witt, S.F., and Witt, C.A. (1995), 'Forecasting tourism demand: a review of empirical research', International Journal of Forecasting, Vol 11, pp 447-475.

Zhang, Q.H., Wong, K.F., and Or, L. (2001), 'An analysis of historical tourism development and its implications for the tourism industry in Hong Kong', Pacific Tourism Review, Vol 5, pp $\underline{15-21 .}$ 